\title{
VICTORIA O FRACASO: LA GUERRA DEL PACÍFICO Y LA AUTORREPRESENTACIÓN CONTEMPORÁNEA DE CHILE
}

\author{
VICTORY OR FAILURE: \\ THE WAR OF THE PACIFIC AND THE CONTEMPORARY \\ SELF-PRESENTATION OF CHILE
}

Daniel Parodi Revoredo*

\begin{abstract}
El presente artículo trata del conflicto que se genera cuando una narración histórica nacional, que le otorga preeminencia a valores como el patriotismo y la heroicidad militar, entra en conflicto con paradigmas del mundo actual, como la universalización de los derechos humanos, la crisis del Estado-Nación, el auge de la globalización y la dispersión del poder. El caso específico que estudiamos en este artículo es el de Chile, cuya historia oficial se discute a la luz de enfoques postnacionales y contemporáneos.

Palabras claves: Discurso histórico, identidad nacional, imaginario colectivo, nacionalismo, narratividad, representación histórico, historiografía tradicional, Chile, Perú, Bolivia.
\end{abstract}

This article deals with the conflict that arises when a national historical narrative, which gives preeminence to values such as patriotism and military heroism, conflicts with paradigms of the world today, such as the universalization of human rights, the crisis of the State-nation, the rise of global globalization and the dispersion of power. The specific case that we study in this article is that of Chile, whose official history today is discussed in the light of postnational and contemporary approaches.

Key words: Historical discourse, National identity, collective imaginary, nationalism, narrativity, historical representation, traditional historiography, Chile, Peru, Bolivia.

\section{Introducción}

"América Latina y nuestros países siguen ligados no solamente a una determinada mirada de la historia, que llega desde el pasado, sino que además pretenden construir la historia del presente y del futuro a partir de esa historia, a lo menos desde el punto de vista diplomático y político respecto de las naciones vecinas" (Eduardo Cavieres).

El 13 de diciembre de 2015 falleció Benedict Anderson, autor de la célebre Comunidades Imaginadas. El recuerdo de su libro, que acuñó un concepto fundamental para pensar la nación y los procesos de construcción nacionales, hizo que me detuviese a repensar la particularidad del nacionalismo chileno cuya comprensión no es posible si no se le relaciona con Perú y Bolivia. Desde la guerra del Pacífico (1879-1883) hasta la actualidad, los tres países han generado un enrevesado nudo de nacionalismo, máxime si entendemos la patria como Jürgen Habermas; es decir, en términos de alteridad, como "al otro del otro" (Anderson 1993 y Jiménez 1998 p. 32).

En este sentido, lo que nos proponemos en estas líneas es comprender cómo Chile escribió su historia oficial adjudicándose el rol de país victorioso en el relato, a base de sus éxitos militares sobre el Perú y Bolivia, y la manera cómo el imaginario de la nación victoriosa ha sido puesto en entredicho por el mundo posnacional que emerge de la Guerra Fría y que cuestiona el paradigma del Estado-Nación desde una mirada más global y universalista.

Este cambio de enfoque ha desafiado al discurso histórico oficial en el contexto específico de los litigios que en 2008 y 2013, respectivamente, le interpusieron Perú y Bolivia a Chile ante la Corte Internacional de Justicia de La Haya: el primero solicitando la delimitación de la frontera marítima bilateral y la segunda exigiendo una salida soberana al Océano Pacífico. De manera indirecta, ambas demandas cuestionan el relato tradicional chileno

\footnotetext{
* Investigación financiada por la Universidad Peruana de Ciencias Aplicadas (UPC). Correo electrónico: parodi.da@pucp.edu.pe
} 
que presenta los acontecimientos del pasado como siempre justos e incuestionables.

Nuestra tesis central es que el Estado chileno, al sentirse amenazado por los nuevos paradigmas que emergen tras el fin de la Guerra Fría, ha adoptado una postura pasadista que se aferra al discurso victorioso de la historiografía tradicional. Esta postura dificulta la ejecución de políticas de reconciliación para superar el pasado doloroso dirigidas hacia Perú y Bolivia, como las que aplicaron los exbeligerantes de la Segunda Guerra Mundial y otros colectivos distanciados por acontecimientos traumáticos (Rosoux, 2002 y 2008).

Para la realización de esta reflexión hemos consultado diversos autores de los que nos hemos servido en investigaciones anteriores y otros que recientemente hemos revisado. Los principales son Jürgen Habermas, cuyo Más allá del Estado Nacional nos proveyó de una interesante definición de lo posnacional en tanto que sociedad que ha superado la conexión entre ciudadanía y defensa militar de la patria, y que se identifica, más bien, con los derechos civiles de los que goza o que debe exigir del Estado (Habermas, 1998). Además, Moisés Naím con El Fin del Poder nos ha provisto una mirada al mundo actual desde el prisma de la globalización, para comprender cómo el EstadoNación decimonónico discurre en un mundo que lo coloca en la periferia de la realidad contemporánea (Naím, 2013).

\section{Del Estado nacional al mundo global}

El debate alrededor del concepto de nación sigue abierto. En 1991, Tzvetan Todorov advirtió la existencia de un nacionalismo interior que se edifica sobre la base de la exaltación de elementos intrínsecos a la nacionalidad, como la lengua, las tradiciones, la culinaria, etc. Sin embargo, en la mayoría de casos la entidad nacional se ha definido en contraposición a otra entidad nacional análoga (nacionalismo exterior): Alemania contra Francia; Perú contra Chile; Panamá contra Colombia, etc. (Todorov, 2013 pp. 203-223). A decir de Habermas (1998):

"la invención del pueblo-nación tuvo un efecto catalizador para la democratización del poder estatal, pues una base democrática para la legitimación de la dominación política no hubiera surgido sin conciencia nacional. Fue la nación la que fundó un contexto o nexo de solidaridad entre personas que hasta entonces habían resultado extrañas" (p. 184).

Si desde el siglo XV Dios se convirtió en el elemento ideológico e irracional que justificó la soberanía del rey sobre los súbditos; con la nación, los liberales de los siglos XVIII y XIX constituyeron un poderoso marco conceptual que, apelando al pasado, la historia y las tradiciones comunes, dotó de sentido a estas nuevas comunidades. El ciudadano, entonces, deja de ser únicamente el poseedor de derechos y deberes pues toma conciencia de su pertenencia a un conjunto, al que le debe su solidaridad.

Es así que la nación le suma a los Estados liberales un elemento que atañe las emociones más profundas como el apego a la tierra, la patria, y que, como señalara Anderson, se comprende mejor si se compara con una profesión de fe religiosa que con la adhesión a los paradigmas ideológicos del siglo XX, como lo fueron el anarquismo o el comunismo (Anderson, 1993, pp. 28-30).

En ese sentido, la libertad individual abdica parte de su soberanía en la libertad nacional, la que solo se entiende en relación o en contra de otro pueblo-nación similar que la amenaza. Es en esta relación en la que me defino como "el otro del otro", cuando le cedo mi libertad individual a la patria, la que puede reclamar mi sangre cuando aquella amenaza esencial cobra realidad mediante las rivalidades nacionales y, finalmente, de la guerra.

\section{Alemania y las cesuras del Estado-Nación}

Jürgen Habermas observa su tiempo desde Alemania. Su ubicación espacio-temporal le otorga una mirada privilegiada, pues es testigo de excepción de dos momentos fundamentales para la historia occidental como el fin de la Segunda Guerra Mundial en 1945 y el de la Guerra Fría en 1989. Lo singular de su atalaya, es que estos dos quiebres civilizatorios esenciales lo son también para la particularidad nacional alemana. No pueden sino serlo, pues ambos puntos de principio/fin tienen lugar en Berlín: la capitulación de la Alemania nazi, así como el derribo de su emblemático muro, y con él, del "mundo de las ideologías".

Es desde esa doble mirada nacional-global que Habermas (1998) califica 1945 y 1989 como años 
de cesuras o de cese, de cambios paradigmáticos. Para él, 1945 supone no solo la caída de Hitler en Alemania sino de un modelo de Estado que podía exigir la sangre de sus hijos en nombre de una libertad superior como la nacional (pp. 49-50).

Ejemplo preclaro de la caída del viejo paradigma y de su reemplazo por uno nuevo lo representa la república de Bohn (RFA), la que inclusive adopta el 8 de mayo -fecha de la rendición de la Alemania nazi- como fiesta nacional (Habermas 1998 p. 176). Es decir, la propia derrota nacional se celebra como liberadora porque le da vuelta a la página de un pasado vergonzante y marca la entrada en vigencia de otro modelo de Estado, el secularizado o postnacional:

Cuando el Estado secularizado, ya sin residuos, deja de reclamar en nombre del colectivo un derecho sobre la vida y la muerte de sus ciudadanos solo entonces puede la idea republicana cobrar la primacía y penetrar y estructurar a su vez, las formas de vida que aseguren la integración social (Habermas 1998, p. 188).

Para Habermas (1998), “... en el Estado-Nación va inscrita una tensión entre el universalismo de la comunidad jurídica igualitaria que el Estado representa y el particularismo de la comunidad histórica de destino que es la nación" (p. 188) y esa tensión se rompe una vez en 1945 y otra en 1989. Su ruptura implica la vuelta metafórica a Rousseau, al ciudadano de a pie cuyos derechos fundamentales y su ejercicio, dentro de los modelos republicano o monárquico parlamentario, es capaz, nuevamente, de ejercer y hacer valer.

Según Habermas (1998), el contexto postnacional es aquel en el que "la autocomprensión del Estado democrático de derecho se separó no solo en la teoría, sino también en amplias capas de la población, de los patrones de autoafirmación nacional...” (p. 189). A esta característica debemos añadirle la superación de la narrativa que presenta a la nación como particularidad histórica, unívoca y hegemónica, para transitar hacia un espacio público mucho más amplio que da lugar a sociedades plurales o a lógicas supraestatales en las que los conceptos de soberanía y frontera pierden parte de la carga de emotividad patriótica que antes poseían.

\section{La problemática nacional en el mundo globalizado}

Sin embargo, la transición del Estado-Nación al Estado secularizado, y del pueblo-nación al pueblo-republicano no es el resultado de una evolución feliz sin más sobresaltos que las cesuras de 1945 y 1989. El orden global que se abre paso desde 1990 pone en tela de juicio incluso las premisas postnacionales hasta ahora esgrimidas. Es el mismo Habermas quien se pregunta si acaso el divorcio entre el ciudadano y el Estado no supone, como piensa J.M. Géhenno (1998): “... el fin de la democracia desde el punto de vista de ciudadanos que han sido despachados del liquidado contexto de la solidaridad estatal..." (p. 192).

A su turno, Zigmunt Bauman sostiene que la bipolaridad ideológica del mundo de la Guerra Fría le otorgó a este la ilusión de una totalidad partida en dos. Es entonces cuando el Estado weberiano, entendido como el gran monopolista de la coerción y de la violencia, alcanza su máximo apogeo, pero, al mismo tiempo, empieza a reconocer sus límites en la universalización, a los que le sobrevendrán, poco después, los de la globalización (Bauman 2001, pp. 79-85).

La universalización remite a la creación de foros multilaterales, los que han proliferado desde la creación de la ONU en 1945, a poco de concluir la Segunda Guerra Mundial. Desde entonces la ONU se ha convertido en el ente supranacional por excelencia, rector del nuevo orden mundial de la postguerra (Bauman 2001 p. 81) ${ }^{1}$.

De acuerdo con el parecer de Zigmun Bauman, la globalización, lejos de consolidar el orden mundial establecido por la ONU, lo ha debilitado al punto de convertirlo en un "nuevo desorden mundial", en el que la misma soberanía del Estado es expropiada por fuerzas económicas y poderes trasnacionales que aquella es incapaz de controlar. De esta manera, se presenta a la globalización como el fin de la soberanía tal y como la planteaba el modelo de Estado weberiano, al punto de reducir su tradicional monopolio de la violencia a la exclusiva finalidad de preservar poderes fácticos, trasnacionales e invisibles (Bauman 2001, pp. 80-87).

Algo más optimista es la mirada de Moisés Naím. Al contrario de lo que señala Bauman, Naím cree que desde el inicio del siglo XXI, el mundo, en general, se ha enriquecido y las clases medias se han ensanchado. Esta situación, señala, ha generado 
un acceso masivo al conocimiento por medio de las TIC, el que corroe los centros de poder tradicionales como lo son el Estado, las burocracias y los partidos políticos.

Simultáneamente, las TIC dotan al ciudadano de grandes oportunidades de informarse y fortalecer sus niveles de autoconciencia acerca de sus derechos civiles. De esta manera es posible presionar los centros de poder e inclusive capturarlos temporalmente, autoconvocándose a masivas manifestaciones, viralizando demandas en las redes sociales, o consolidando súbitos y enormes movimientos políticos como pueden serlo la campaña por el Brexit en Inglaterra, la conformación de las organizaciones políticas Podemos y Ciudadanos en España y, años antes, la primavera árabe (Naím 2013, pp. 85-89).

De esta manera, la circulación de la información $\mathrm{y}$ del conocimiento por las redes sociales nos remite a una dimensión que, bajo los códigos propios del siglo XXI y de las tecnologías de la información, establece vasos comunicantes con la democracia directa de los antiguos griegos, la de los franceses de la Comuna de París, la de los suizos contemporáneos, tanto como con la definición de lo posnacional de Jürgen Habermas.

Ya sea desmedida o reducida su influencia en el contexto del poder global, lo cierto es que el siglo XXI le abre paso a un ciudadano independiente de su viejo pacto de sangre con la nación y lo acerca más al sujeto consciente y defensor de los derechos civiles, los que no han dejado de universalizarse desde mediados del siglo XX hasta la fecha (Habermas 1998, pp. 189).

Finalmente, queda preguntarnos ¿cuál es el campo de acción del Estado-Nación ante la arremetida de la globalización?, ¿simplemente ha desaparecido?, ¿se ha conformado con resignar su viejo rol rector de la vida social para desempeñar, con ropaje contemporáneo, el de simple gendarme de los intereses burgueses que le quisieron asignar Adam Smith y los teóricos liberales del siglo XIX, el mismo que se recicla en el nuevo rostro del mundo global?

Las respuestas son múltiples porque la nación no ha desaparecido por completo como referente identitario, ni el Estado ha dejado de ejercer el monopolio de la violencia, ni de administrar servicios básicos como la infraestructura para el desarrollo, la salud y la educación. De esta manera, en el último tercio de la década de 2010 pareciera que el Estado -aunque debilitado ante el poder global-se reacomoda en un contexto distinto y limitado en comparación con las fortalezas de las que disfrutó en las dos centurias precedentes.

Una de las respuestas posibles del Estado ante el desafío global es elegir la senda que lleva de regreso al pasado y a las certezas de la historia por tenérseles como lo único seguro en un presente marcado por el acelerado cambio tecnológico y la rápida obsolescencia de todo lo que nos resulta útil para vivir (Jiménez en Habermas 1998 p. 35, Habermas 1998 p. 195).

Y de eso trata nuestro ensayo, de la respuesta al mundo global de un Estado moderno, Chile, cuando trata de adaptarse a un escenario cambiante y que solo puede descifrar al relacionarse con sus otros, sin estos no se entienden ni sus tradiciones ni su potente apego a la historia nacional: Perú y Bolivia.

\section{Victoria o fracaso}

El 25 de noviembre de 2015 el exagente de Chile ante la CIJ para el caso interpuesto por Bolivia en 2013, José Miguel Insulza, le dio al mundo lo que parecía ser una buena noticia: señaló que "hay que contrarrestar la imagen de que actuamos como una fortaleza sitiada". Con ello, no solo aludió el imaginario nacional de la excepcionalidad chilena del que nos ocuparemos más adelante, sino que puso en tela de juicio la política exterior de su país, más específicamente, la que lo vincula con los Estados vecinos y de la región sudamericana ${ }^{2}$.

En esa misma línea, el ex-Secretario General de la OEA señaló que Chile se encontraba abierto al diálogo y alcanzó a reconocer que adolecía de una línea comunicacional con el exterior, tanto como que le hacía falta "decisiones más estratégicas de política vecinal". En el mundo globalizado, Chile había decidido replantear su posición en el concierto de las naciones (Insulza 2015).

Sin embargo, meses después, en julio de 2016, el mismo Insulza dio marcha atrás y, en el marco del complejo litigio entre Chile y Bolivia en la CIJ, anunció a la prensa internacional que su país aludiría la Guerra del Pacífico en su Contramemoria ante dicho tribunal de justicia.

Conforme con sus declaraciones al diario $E l$ Mercurio, Chile explicaría la historia de sus límites con su vecino altiplánico desde 1842 hasta el inicio del referido conflicto bélico, para así justificar el inicio de la guerra a base del incumplimiento boliviano, en 1878, de un tratado bilateral firmado cuatro años antes, en 1874 (Insulza 2016). De 
acuerdo con la versión oficial chilena de la Guerra del Pacífico, dicha contravención habría precipitado su estallido pocos meses después, el 14 de febrero de 1879 , cuando sus fuerzas militares desembarcaron en Antofagasta y ocuparon Atacama, la entonces provincia litoral boliviana.

En efecto, la Contramemoria de Chile fue presentada a la Corte Internacional de Justicia de La Haya, por su entonces canciller Heraldo Muñoz, el día anterior a las declaraciones de Insulza, el 13 de julio de 2016. Esta dedica el capítulo II de su primer volumen a explicar las razones que tuvo Chile para iniciar la Guerra del Pacífico (pp. 10-19). En este punto es preciso remarcar que la Memoria de Bolivia, presentada a la CIJ algo más de dos años antes, el 15 de abril de 2014, también dedica un capítulo completo, el primero de su primer volumen, a explicar la historia de la pérdida de su cualidad marítima a manos de Chile. En ese sentido, resultaba complicado para el Estado chileno dejar sin responder la argumentación boliviana en ese aspecto específico (pp. 12-18).

En todo caso, el discurso histórico que expresa Chile en su Contramemoria es básicamente el tradicional. En esta línea, se denuncia la victimización de Bolivia debido a la pérdida de su cualidad marítima, tanto como se subraya las inexactitudes que presenta su narración de los acontecimientos. Seguidamente, se justifica el emprendimiento de la guerra bajo el argumento de que esta no constituyó un hecho aislado y se afirma, por el contrario, que fue común, en el siglo XIX, que los nuevos Estados sudamericanos fijasen sus fronteras recurriendo a la violencia militar.

Poco después, la Contramemoria intenta contrarrestar la imagen belicosa que la memoria boliviana le asigna a Chile, resaltando su apoyo a Perú y Bolivia en la gesta independentista. Este se produjo cuando su libertador, Bernardo O'Higgins, envío parte de su ejército al Perú, bajo el mando del libertador argentino José de San Martín, a luchar por la consolidación de la independencia americana. $\mathrm{Al}$ mismo tiempo, destaca la actitud americanista de Chile durante la guerra que libró, junto con Perú, Bolivia y Ecuador en contra de España entre 1864 y 1866.

Luego, la Contramemoria se vuelca de lleno al análisis de las causas de la guerra de Pacífico y reproduce los tópicos fundamentales de la historiografía tradicional chilena. Inclusive el argumento de la mayor población de sus connacionales en el desierto de Atacama, como justificación de su anexión militar, aparece esbozado en el documento:
"La région d'Atacama était restée largement inhabitée jusqu'à la découverte d'importants gisements de guano dans les années 1840, qui a entraîné un afflux considérable de migrants en provenance du Chili. Dans les années 1870, sa population était ainsi majoritairement composée de travailleurs chiliens" (p. 14).

Finalmente, el alegato de Chile deposita la responsabilidad del estallido de la Guerra del Pacífico sobre sus oponentes. En tal sentido, se explicita que la violación del tratado de 1874, por el impuesto al salitre exportable por el puerto de Antofagasta, decretado por el presidente de Bolivia Hilarión Daza, desencadenó el conflicto y que, respecto del Perú, no le quedó otra alternativa a Chile que abrirle también hostilidades el 5 de abril de 1879, pues el día anterior el vecino había advertido que se encontraba en "estado de guerra".

Como parece claro, en estas líneas no vamos a discutir las razones jurídicas de la Guerra del Pacífico, pues entendemos la apelación a la prueba documental para justificar o refutar causas pretéritas, como un recurso narrativo propio de escuelas historiográficas superadas, como el positivismo histórico. Por el contrario, notamos que sus características resultaron útiles a los relatos nacionales decimonónicos que ponderaron que la viabilidad del proyecto político liberal pasaba más por la generación de arraigos patrióticos que por la formación de ciudadanos deseosos de defender la universalidad de los derechos del hombre.

Al respecto, un aporte imprescindible en la deconstrucción de los relatos oficiales de la Guerra del Pacífico es el trabajo de Rodrigo Naranjo (2011), quien explora los discursos tradicionales de Chile, Perú y Bolivia acerca de esta conflagración, subrayando, para cada caso, su dimensión narrativa y sus particularidades, alejándolas del viejo criterio de verdad histórica -demostración documental- tan reiterativos en el enfoque positivista.

En esa línea argumental, Naranjo señala que los relatos de la Guerra del Pacífico no se limitan a recrearla, sino que proyectan a las sociedades discursos acerca de su presente estableciendo varias de categorías "(...) utilitaristas, organicistas, clasistas y racistas". Además, dichos relatos ofrecen, en 
sus entrelíneas, una interesante aproximación a los eventuales cambios de los discursos e imaginarios nacionales con el tiempo (pp. 29-30).

En esa misma línea, en dos trabajos que publicamos en 2010, analizamos las narrativas peruana y chilena respecto de la Guerra del Pacífico, las que encontramos harto influenciadas por el nacionalismo, el positivismo y el romanticismo decimonónicos. Asimismo, obtuvimos, de sus entrelíneas, una muy clara construcción del imaginario del yo y el otro -alteridad-, con la finalidad de posicionar al primero en un lugar de preeminencia respecto del segundo.

No obstante, la diferencia que encontramos entre ambas narrativas es su vínculo con la realidad que refieren, la que remite a la posición desde donde se observa o se vive dicha realidad. Es así que la versión chilena de la Guerra del Pacífico se escribe desde la victoria, mientras que la peruana desde la derrota. De allí que un discurso se caracteriza por la exaltación de la nación guerrera a la vez que civilizada y el otro, por el contrario, es hipercrítico de la propia conducción político-militar antes y durante la conflagración, al mismo tiempo que denuncia enfáticamente la agresión que sufrió a manos del contrario. Luego, la poesía romántica del relato, la exaltación de héroes militares y el esfuerzo por construir un imaginario coherente y funcional que resalte los valores del propio sujeto nacional, en contraposición con sus otros, son básicamente similares en ambas narrativas.

A una conclusión parecida ha llegado Juan Carlos Arellano (2015), quien analiza los discursos de la Guerra del Pacífico del Perú, Chile y Bolivia. Acerca de la narrativa chilena apunta que:

Efectivamente, la mirada extrovertida del nacionalismo chileno necesitó de una cuantiosa dosis de particularismo, para darle sentido al conflicto y motivar así a sus ciudadanos a realizar sacrificios extraordinarios. La característica exógena del discurso se complementó como mirada endógena, que realiza una reflexión introspectiva, en la historia nacional que fue narrada con un marcado sentido de alteridad. La historia nacional se transforma en un insumo crucial para el diseño de los discursos, la que al mismo tiempo es utilizada como arma ideológica capaz de legitimar el conflicto, otorgándole un sentido que está por sobre las causas circunstanciales que lo provocan (p. 72).

Desde una mirada cercana a los postulados de la posmodernidad, nosotros adherimos la idea que presenta la realidad fragmentada y al concepto de historias en plural, y que sugiere que una infinidad de narraciones del pasado luchan por posicionarse en el debate presente para ubicarse dentro del complejo tablero de un juego dialéctico que rechaza verdades absolutas para darle la más amplia cabida al universo interpretativo (Beltrán 2001).

Es por ello que sostenemos que la decisión de argumentar la razón del propio relato oficial de la Guerra del Pacífico en la CIJ, tanto en el caso boliviano como en el chileno que es el que nos ocupa, contiene el recurso de la vuelta al pasado. Este supone guarecerse en la trinchera de la historia y asumir posiciones defensivas ante un mundo que se maneja con otros códigos comunicacionales, éticos y morales. Desde esta nueva mirada, la épica victoria que obtuve en una infausta conflagración militar, en la que hasta apenas ayer cobijé mi orgullo nacional, pudiese no resultar tan admirable a ojos extraños, cuyos códices pasan más por la universalización de los derechos humanos, por la conciencia de los derechos civiles y por el rechazo de toda forma de violencia.

Hablamos de un mundo global, saturado de información que va y viene, en el que Chile adopta una posición defensiva. Sin embargo, el supuesto agresor no es más el país que sitia a la fortaleza sino un presente que ya no observa el pasado con la mirada nacionalista de las centurias anteriores y al que, por esta razón, no comprendemos y nos aterra.

\section{El orden y la excepcionalidad: la narrativa nacional chilena}

Las imágenes del orden, de la excepcionalidad chilena en la región sudamericana, tanto como la del país guerrero, que defiende con valentía sus fronteras cuando son amenazadas, constituyen el corazón de su discurso histórico oficial, magistralmente analizada en varios artículos de la compilación de Gabriel Cid y Alejandro Santa María titulada Nación y nacionalismo en Chile (2009).

Se aprecia, en sus ensayos, cómo desde la república temprana van apareciendo y reuniéndose los episodios en los que se cimienta el potente imaginario de la nación victoriosa que se alza 
sobre los preceptos de la razón ilustrada y que es capaz de construir instituciones liberales sólidas en condiciones adversas. Chile es un país cercado por infranqueables fronteras naturales como el océano Pacífico y la cordillera de los Andes, y amenazado por la hostilidad manifiesta o latente de dos rivales perpetuamente irredentistas, los que me hacen comprender quién soy yo y, además, por qué soy excepcional: Bolivia y Perú (Cid \& Santa María 2009; Parodi 2010).

\begin{abstract}
"María José Scheneuer ha analizado la imagen sobre la excepcionalidad chilena dentro de Latinoamérica emanados desde las páginas de El Mercurio de Valparaíso en la década de 1840. (...) la autopercepción chilena de ser la "excepción honrosa en América (...) se constituyó en una idea fuerza en torno a la cual se articularon los discursos sobre lo nacional" (Cid \& Santa María 2009, p. XXI).
\end{abstract}

La narración de la Guerra del Pacífico se suma al discurso y lo enriquece, pues se erige en ejemplo del triunfo de la nación civilizada sobre los vecinos bárbaros, y del elemento occidental sobre el aborigen. Es también la victoria de la razón y el derecho. En concordancia con la autoimagen del yo, una guerra, y, su consecuente victoria, no pueden sino ser el resultado natural de un emprendimiento justo, legítimo e indiscutible, tanto como de un espíritu guerrero preexistente que es motivo del orgullo nacional (Parodi 2010, pp. 67-69 y Villalobos 2004).

"La racionalidad que se manifiesta en el espíritu de equilibrio y moderación se combina (...) con el aprecio del valor guerrero. Según palabras de Manuel Salas, el pueblo chileno se caracterizaba por un especial valor heroico que tenía su origen en la prolongada guerra entre los españoles y araucanos. (...) Los chilenos tenían cierta conciencia de que (...) Chile había sido una tierra de guerra" (Krebs en Cid \& Santa María 2009, p. 12).

Asimismo, la Guerra del Pacífico representa en el imaginario chileno la causa y la consecuencia del éxito del proyecto nacional. La causa porque su estallido remite al orden inicial, a la claridad geopolítica, al sentido de la justicia y al apego al derecho, los que, combinados, explican la victoria sobre dos países territorial y poblacionalmente más grandes, lo que le añade una importante cuota de heroicidad al relato y genera, en el imaginario, la recurrente analogía con el triunfo de David sobre Goliat (Parodi 2010 pp. 35-43).

Respecto de las consecuencias, la victoria se constituye en la oportunidad de enriquecer las finanzas públicas con los recursos naturales -el guano y el salitre- obtenidos de los territorios anexionados para así impulsar el proceso de construcción y expansión del Estado. De esta manera, una vez concluida la guerra, las fuerzas que invadieron el Perú, recién retornadas, fueron transferidas hacia el norte mapuche, de manera que el Estado chileno logró extender su autoridad a lo largo de todo su territorio (Sagredo 2014, p. 193).

Cumplido este objetivo, el proyecto de estadonación liberal se había cumplido, lo que facilitó que debido a la amalgama de varias circunstancias aparentemente positivas o favorables forjasen un discurso oficial victorioso que presenta la historia de Chile como "un cúmulo ininterrumpido de aciertos que no deja cabida al error" (Parodi 2010, p. 85).

Este razonamiento -la funcional sinergia, desde una perspectiva nacionalista, entre los eventos y su relato- explica que Chile pocas veces se haya planteado las preguntas que ahora, desde la universalización, le plantea indirectamente la Corte Internacional de Justicia: ¿y los otros? ¿Y Perú y Bolivia? ¿Les infligí daño a mis vecinos durante la Guerra del Pacífico? ¿Por qué me demandan ante la CIJ? Entonces estamos listos para volver a las cesuras de Habermas, aplicadas a una compleja realidad trinacional.

\section{Pinochet y juventudes rebeldes: las cesuras chilenas}

Recientemente revisé la Historia mínima de Chile, del historiador Rafael Sagredo, que responde a la actual demanda de historias nacionales de difusión, aptas para todo público, pero dotadas también de una mirada nueva, más a la luz de los paradigmas contemporáneos que analizamos en la primera parte de este ensayo.

¿Por qué elijo una obra de estas características para enriquecer mi análisis? Porque me interesa conocer el estadio en que se encuentra el discurso actual, y por actual no me refiero a uno promovido necesariamente desde el Estado, sino al que escribe 
el historiador cuando se dirige al gran público que le pide un resumen, una apretada síntesis. ¿Cuál es el discurso apto para el consumo masivo?, ¿cuál es el relato aceptable? y ¿cuál es la crítica a la vieja historia que el autor comunica a la comunidad y que esta está en posición de asimilar?

En el texto de Sagredo conviven dos esquemas no necesariamente sinérgicos: uno intenta situar los principales acontecimientos de la historia republicana de Chile en una lógica de continuidad casi cíclica. De este modo, se sugiere que el Chile independiente ha experimentado periodos de expansión, los que, a su vez, ceden el paso a fases críticas que devienen en autoritarismos y así sucesivamente.

Dentro de esa lógica, no se presenta necesariamente a la dictadura de Augusto Pinochet como el quiebre de un sistema de creencias preexistente sobre la propia sociedad, cuyas bases son la civilización, el apego a la ley y la vieja idea ilustrada del progreso, sino como el resultado de un ciclo de crecimiento que también se produjo en la década de 1830 y 1920, lo que explica las sendas dictaduras de Diego Portales y Carlos Ibáñez (Sagredo 2014).

A pesar de ello, la polarización hasta ahora vigente entre adeptos y detractores de Augusto Pinochet sugiere que el debate alcanzó la autoimagen del yo o nosotros colectivo de Chile. De este modo, la narrativa histórica oficial, cuyos principales tópicos hemos ya reseñado, no pudo sino cuestionarse a la luz de la violencia irracional ejercida desde el Estado hacia la población durante aquella dictadura militar (Sagredo 2014, pp. 258-262).

El segundo esquema de Sagredo establece con claridad un fascinante punto de quiebre entre el Chile de ayer y el de hoy, y que fuerza la revisión del discurso histórico dominante. En tal sentido, las protestas callejeras de las juventudes escolar y universitaria de los sectores medios y bajos exigiendo una mayor inversión del Estado en su formación, representa, para Chile, una crítica al metarrelato moderno de la nación de guerra, homogénea y civilizada, el que cede posiciones frente a una realidad que presenta grandes desigualdades sociales.

Las movilizaciones juveniles, generadas por el acceso masivo a las TIC, han puesto en evidencia las contradicciones de una sociedad dividida por las posibilidades de acceder a una educación de calidad. En tal sentido, para Sagredo, Chile repentinamente dejó de ser la copia feliz del Eden ${ }^{3}$ y asiste al divorcio entre el antiguo relato del Estado-Nación victorioso y una cotidianidad en la que la igualdad de oportunidades se percibe como una ficción (Sagredo 2014, pp. 269-272).

De esta manera, Sagredo coloca a Chile en una encrucijada de historia, en la que el relato de la nación victoriosa es puesto en tela de juicio por generaciones que se formaron en el mundo de la post-Guerra Fría y las TIC, las que han debilitado la capacidad del Estado para ejercer el poder y difundir exitosamente un discurso histórico homogéneo y aglutinador.

La autoconciencia de sí, potenciada por las TIC, le ha permitido a la juventud chilena desarrollar una importante capacidad de movilización alrededor de una agenda concreta bastante bien estructurada y no supeditada a las plataformas de los partidos políticos. De esta manera, la sociedad chilena contemporánea asiste a una cesura sociopolítica que, entre otros derroteros, espera que le vuelvan a contar su historia por distintas bases morales e ideológicas y participar de este significativo ejercicio narrativo (Naím 2013, pp. 120-157).

\section{A manera de conclusión: la esfera nacional y sus límites}

En Lo que dicen de nosotros he señalado que los imaginarios nacionales tienden a personificar a los países, esto es, a utilizar la figura retórica de la personificación para dotarlos de temperamentos con características específicas como la agresividad, el ánimo conspirativo, ser justo, equitativo, etc. Mediante este recurso literario la nación propia y las vecinas son imaginadas por la colectividad (Parodi 2010, pp. 28-29).

Sin embargo, con el advenimiento de la era posnacional y de la sociedad del conocimiento, las representaciones de los países, y sus rivalidades, han perdido terreno y se han convertido en apenas una entre diversas dimensiones de la realidad, por lo que influye en la vida de los connacionales mucho menos de lo que podía hacerlo antes de 1945 o 1989. El mundo global ha debilitado sensiblemente la capacidad de ejercer el poder desde el Estado no solo por medio del monopolio de la violencia, sino de la difusión de un relato hegemónico del pasado nacional (Naím 2013 y Bauman 2001).

Al mismo tiempo, la difusión de las TIC ha multiplicado el acceso a la información a grandes segmentos de población que ahora pueden informarse, movilizarse y exigir sus derechos. Gracias 
a las TIC, cada vez son más las personas "conectadas", lo que supone un distanciamiento de la esfera estatal, tanto como el desarrollo de la capacidad de demandar al gobierno la mejora o multiplicación de sus servicios.

La reducción del área de influencia de la dimensión estatal-nacional es evidente en las relaciones bilaterales peruano-chilenas. Sus economías se han venido integrando incesantemente desde hace dos décadas, mientras que, en el plano social, el intercambio de personas y mercaderías entre Tacna y Arica se ha elevado exponencialmente. Asimismo, el volumen de las inversiones bilaterales no ha dejado de incrementarse, ni siquiera en periodos críticos como el litigio ante la CIJ (2008-2014), al punto que hace poco se inició una nueva etapa de cooperación con el viaje del expresidente peruano Pedro Pablo Kuzcynski a Santiago de Chile en noviembre de 2016. En su visita oficial al país vecino, Kuzcynski acordó con su homóloga chilena Michelle Bachelet una potente agenda integracionista que incluye la realización periódica de gabinetes binacionales, la reactivación del mecanismo $2+2$, entre otras medidas. De hecho, en julio de 2017 la expresidenta de Chile, acompañada por todos sus ministros, visitaron Lima, devolviendo así la cortesía al mandatario peruano.

Al mismo tiempo, en la última década hemos asistido a la multiplicación de estudios y de grupos de investigación binacionales -cuyos miembros son académicos de los países que libraron la Guerra del Pacífico-y que han puesto sobre el tapete tanto los estudios regionales alrededor de la triple frontera como a actores sociales y étnicos, como es el caso del intercambio cotidiano entre tacneños y ariqueños, o el desenvolvimiento de la etnia aymara muchas veces dividida, o unida, por su ciudadanía indistintamente peruana, chilena o boliviana.

Estos estudios no se limitan a estudiar la Guerra del Pacífico desde una perspectiva regional, sino que acercan a los actores del presente mediante encuentros entre comunidades y escuelas. En resumidas cuentas, la voz que nos llega de la triple frontera nos habla de una realidad presente que debería ser tomada en consideración al momento de escribir relatos del pasado con características decimonónicas que tienden a distanciarnos, cuando, por el contrario, la cotidianidad potencia día a día la integración social, económica y cultural entre las poblaciones fronterizas de nuestros tres países (Gonzáles \& Ovando 2008, 2016 y 2018).
Sin embargo, la cuestión chilena-boliviana nos parece más complicada porque actualmente ambos países litigan en la CIJ y porque Bolivia ha construido su yo o nosotros colectivo a base de la cuestión marítima. Este es un caso modélico de la tesis del nacionalismo exterior de Tzvetan Todorov, que sostiene que la nación es tal en tanto existen otras que la amenazan (Todorov 2013, pp. 203-223).

Bolivia es nación, en primer lugar, porque quiere acceder con soberanía al Océano Pacífico desde las costas de Chile, ya que este país la privó de su cualidad marítima en la guerra del 79. De esta manera, la relación chileno-boliviana es particular, pues predomina en ella la esfera nacional en un periodo en el que la globalización y el universalismo han ubicado al paradigma nacionalista en posiciones periféricas:

La nación nuestra se constituyó bajo la idea de una pérdida de algo que la había mutilado, como si le hubieran quitado un brazo; de hecho, alguien ha dicho que si la nación boliviana desapareciera y quedara un solo boliviano diría "algo falta", y es el mar (Rodríguez en Cavieres 2016, p. 32).

Habiendo establecido que la dimensión nacional es una entre tantas otras en el mundo contemporáneo, paso a ocuparme de Chile y sus cesuras. No creo estar forzando el concepto de cesura que Habermas aplica a acontecimientos que devienen en cambios paradigmáticos de la civilización occidental y que la hacen transitar de una cierta episteme a otra distinta. En América Latina, los Estados-Nación mantienen vigencia a pesar de haberle cedido la iniciativa al mundo global, de manera que las historias nacionales, aunque distan de copar el universo de referencias del individuo, siguen siendo importantes en la construcción de la identidad personal y grupal. Hasta la actualidad, dichos estados son particularidades históricas muy concretas, por lo que pueden generar sus propias cesuras.

Respecto de Chile, notamos una cesura y una no cesura. La cesura se produce cuando se populariza la crítica a la imagen del yo nacional. Este afán revisionista brota de generaciones que han producido un discurso que prioriza una mirada crítica al clasismo que divide la sociedad y que denuncian la desigualdad de oportunidades generada por notables asimetrías en la calidad y costos de los servicios estatales, principalmente los educativos. 
De allí que el discurso oficial de la nación homogénea, civilizadora y occidental resulte cuestionado, abriéndose un espacio a la difusión de narraciones menos condescendientes con el viejo imaginario del país unificado y victorioso.

En cambio, la no cesura se expresa en el apego del Estado al discurso oficial, asociado a imaginarios como la superioridad frente a los países vecinos y el orgullo por el orden y el carácter guerrero de la sociedad. Este apego encuentra explícita manifestación en el litigio ante Bolivia en la Corte Internacional de Justicia, tribunal al que Chile expone su narración histórica oficial bajo la forma de argumentación jurídica, así como lo ha hecho Bolivia.

George Gadamer señala que donde prevalece la tradición languidece la interpretación y es así que Chile discurre entre los paradigmas opuestos del nacionalismo y la globalización. Por una parte, la sociedad chilena contemporánea se cuestiona la representación tradicional del yo nacional, por la otra, los imaginarios que representan al otro se han modificado muy poco: Perú y Bolivia siguen siendo irredentos y revanchistas (Gadamer 2007, pp. 41-46).

Así pues, la cesura chilena parece interior, hacia adentro de sí, pero en su relación con los países vecinos prevalece la versión oficial, lo que da lugar a la problematización que le da el título a este ensayo: "Victoria o Fracaso". En otras palabras, Chile asiste a un mundo en el que el orgullo nacional por las victorias épicas tiene poca cabida. Frente a esta nueva realidad, el Estado elige atrincherarse en el pasado glorioso antes que revisar el discurso tradicional pertinente a la Guerra del Pacífico desde enfoques más plurales, universalistas e inclusivos.

La anterior afirmación no desconoce que en Chile existe una importante corriente revisionista de la historiografía tradicional, y en específico de la historia de la Guerra del Pacífico, así como potentes esfuerzos, inclusive binacionales y trinacionales, para acercar su país al Perú y Bolivia por medio del rescate de capítulos históricos en los que primaron el acercamiento y la confianza mutua. Ejemplificadora de estos esfuerzos es la trayectoria integracionista del Dr. Eduardo Cavieres, Premio Nacional de Historia en su país, que recientemente ha dado cabida a una compilación de homenaje (Cáceres \& Vito 2016) y del Dr. Sergio González, que ostenta la misma distinción, y con quien tuve la satisfacción de publicar Las historias que nos unen, compilación que reunió a casi treinta académicos de Perú y Chile, quienes destacaron episodios históricos positivos de la relación bilateral ${ }^{4}$.

Lo que señalo, más bien, es que este esfuerzo no ha logrado aún desplazar a la narrativa oficial de su posición central en la representación histórica de Chile, la que se mantiene incólume y se abstiene de preguntarse por el otro y por el daño infligido a las sociedades vencidas en la Guerra del Pacífico. Es por eso que hasta hoy no se ha realizado ningún ejercicio oficial entre las partes para ponerse la una en el lugar de la otra y viceversa, y, de esta manera, conociéndose y acercándose más, concertar los gestos bilaterales necesarios para cerrar las heridas del pasado, más allá de que estas pudiesen parecer, como es natural, más profundas entre los descendientes de quienes perdieron el conflicto ${ }^{5}$.

De hecho, si entender el ayer como una trinchera patriótica parece desfasado en los albores del siglo $\mathrm{XXI}$, tampoco el negacionismo -entendido como el desconocimiento o indiferencia ante acontecimientos dolorosos del pasado- resulta adecuado para superar la desconfianza mutua entre países cuya interrelación socioeconómica es un hecho consumado. Es por eso que quisiera terminar con unas líneas dedicadas a la reconciliación, entendida como un área del conocimiento con amplio desarrollo y que ha devenido en políticas públicas aplicadas con la finalidad de acercar sociedades que sostuvieron conflictos bélicos en su pasado común (Rosoux 2002 y 2008).

El mundo contemporáneo tiene un marco propio de valores como los derechos humanos y la cultura de paz, que puede colisionar con relatos nacionales de corte épico y patriótico que se escribieron a lo largo del siglo XIX. Ese conflicto lo viven cotidianamente Chile, Bolivia y Perú.

Tomar posición en la trinchera de la historia supone la adherencia a una antigua e inamovible tradición que no puede someterse al escrutinio público, menos aún si este se genera extramuros del yo colectivo. Por ello, mientras más cerca nos situemos del campo de irradiación de relatos nacionales patrióticos, más lejos estaremos de la posibilidad de reconciliarnos y cerrar las heridas del pasado doloroso.

El caso chileno -al igual que el peruano y el boliviano- es expresión palpable de cómo en América Latina los procesos de construcción nacionales distan de haber concluido y obstaculizan, aunque 
no necesariamente impiden, la profundización de procesos de integración y reconciliación que resultan fundamentales para adoptar posiciones expectantes en el mundo contemporáneo. En nuestro caso, que es el de Chile, Bolivia y Perú, integración y reconciliación son dos sustantivos que funcionan mejor cuando aparecen juntos, esforcémonos por colocarlos el uno al lado del otro, así lograremos dejar atrás la desconfianza mutua y veremos el futuro como un camino por recorrer en conjunto.

\section{Referencias Citadas}

Anderson, B.

1993 [1983] Comunidades imaginadas: reflexiones sobre el origen y la difusión del nacionalismo. México, D.F. Fondo de Cultura Económica.

Arellano. J.C.

2015 El pueblo de "filibusteros" y la "raza de malvados": Discursos nacionalistas peruanos y chilenos durante la Guerra del Pacífico (1879-1884). Diálogo Andino (45) Recuperado de http://dx.doi.org/10.4067/S0719-26812015000300008 [Consulta: 4 de junio 2018].

Bauman, Zygmunt. 2001 [1998] La globalización. Consecuencias humanas. 2da ed. México, FCE.

Beltrán, Miguel Ángel.

2002 Pensar la Historia en ¿tiempos posmodernos? Memoria y civilización, 04, 19-41.

Cáceres J. y Jaime V.

2016 Pensar la historia. Teoría, análisis y prácticas. Homenaje a Eduardo Cavieres. Valparaíso, PUCV.

Cavieres, E. (ed.).

2013 Conversaciones en Lima. La historia como instrumento de integración chileno-peruana. Valparaíso, Ediciones Universitarias de Valparaíso y PUCV.

Cavieres, E. (ed.)

2014 El fallo de La Haya. Una mirada hacia el futuro. Valparaíso, Ediciones Universitarias de Valparaíso.

Cavieres, E. (ed.).

2016 La historia y la escuela. Integración en la triple frontera: Bolivia, Chile y Perú. Iquique, Universidad de Tarapacá.

Cid G. \& San Francisco A. (ed).

2009 Nación y nacionalismo en Chile. Siglo XIX. 1. Santiago, Centro de Estudios Bicentenario.

Cour Internationale de Justice.

2016 Affaire relative a l'obligation de négocier un accès à l'Océan Pacifique (Bolivie c. Chili). Contre-Mémoire de la République du Chili. Vol 1. Recuperado de http://www. icj-cij.org/files/case-related/153/153-20140417-WRI-0100-FR.pdf [Consulta: 3 de junio 2018].

Cour Internationale de Justice.

2016 Affaire relative à l'obligation de négocier un accès à l'Océan Pacifique (Bolivie c. Chili). Mémoire du Gouvernement de L'Etat Plurinational de Bolivie, vol. 1. Recuperado de http://www.icj-cij.org/files/caserelated/153/153-20160713-WRI-01-00-FR.pdf [Consulta: 3 de junio 2018].

Gadamer, H.G.

2007 [1993] El problema de la conciencia histórica. 3a ed. Madrid, Tecnos.

González, S. \& Parodi, D. (Comps.).

2014 Las Historias que nos unen. 21 relatos para la integración entre el Perú y Chile. Lima, Fondo Editorial PUCP.
González, S. \& Ovando, C.

2018 "El papel de la paradiplomacia entre el norte de Chile y el sur del Perú: antecedentes históricos, limitaciones y nuevos desafíos postfallo de La Haya". Diálogo Andino (55). Recuperado de http://dx.doi.org/10.4067/S071926812018000100079 [Consulta: 6 de junio 2018].

González, S. Ovando, C \& Ross. C.

2016 "La cuestión del río Lauca desde la perspectiva multiescalar: un juego de suma cero de las diplomacias boliviana y chilena”. Diálogo Andino (51). Recuperado de http://dx.doi. org/10.4067/S0719-26812016000300057 [Consulta: 5 de junio 2018].

González, S. Ovando, Rouviere, L.

2008 'De 'aymaras en la frontera' a 'aymaras sin frontera'. Los gobiernos locales de la triple frontera andina (Perú, Bolivia y Chile) y la globalización". Diálogo Andino (31). Recuperado de https://dialnet.unirioja.es/servlet/ articulo?codigo=3341669 [Consulta: 5 de junio 2018] .

Godoy, M.

2011 "Ha traído hasta nosotros, desde territorio enemigo, el alud de la guerra": confiscación de maquinarias y apropiación de bienes culturales durante la ocupación de Lima, 1881-1883. Historia 44: vol. II, julio-diciembre, 287-327.

Habermas, J.

1998 Más allá del Estado nacional. México, FCE.

Hobsbawm, E.

2009 [1999] La era de las revoluciones 1789-1848. 6ta ed. Buenos Aires, Crítica.

Méndez, C.

2009 Héroes del Silencio. Los Veteranos de la Guerra del Pacífico (1884-1924). Santiago Ediciones. Centro de Estudios Bicentenario.

Naím, M.

2013 El fin del poder. Lima, Debate.

Naranjo. R.

2011 Para desarmar la narrativa maestra. Un ensayo sobre la guerra del Pacífico. San Pedro de Atacama. Qillqa.

Ortega, L.

2003 Chile en la ruta al capitalismo. Cambio, euforia y depresión. Santiago, Centro de Investigaciones Barros Arana.

Parodi Revoredo, Daniel.

2010 Lo que dicen de nosotros. La Guerra del Pacífico en la historiografía y textos escolares chilenos. Lima. UPC.

Parodi Revoredo, Daniel.

2010 La república frustrada y el enemigo perverso. La Guerra del Pacífico en la Historia de la República de Jorge Basadre. Revista Summa Humanitatis, vol. 4 (1) Recuperado de http:// revistas.pucp.edu.pe/index.php/summa_humanitatis/article/ view/2306 [Consulta: 5 de junio 2018]. 
Rivera Olguín, Patricio.

2011 La Guerra de 1879 y la integración: desde la enseñanza de la historia. Iquique, Fondo Regional de Cultura.

Rosoux, V.

2008 Pieges et ressorces de la memorie dans les relations internationales. Revue internationale et stratégique (46), 43-50 Recuperado de https://www.cairn.info/revue-internationaleet-strategique-2002-2-page-43.htm [Consulta: 5 de junio 2018].

Rosoux, V.

2008 Introduction: negotiation et reconciliation. Négociations, (9), 7-11 Recuperado de https://www.cairn.info/ revue-negociations-2008-1-page-7.htm [Consulta: 5 de junio 2018].

Sagredo Rafael.

2014 Historia mínima de Chile. México, el Colegio de México.

Todorov, $\mathrm{T}$.

2013 [1991] Nosotros y los otros. Reflexiones sobre la diversidad humana. Madrid, Biblioteca Nueva.

Villalobos, Sergio.

2004 Chile-Perú. La historia que nos une y nos separa. Santiago, Editorial Universitaria.

\section{Notas}

1 Bauman es pesimista respecto de la vigencia de un orden mundial universalista el que habría sido básicamente superado por el desorden de la globalización mundial. Nosotros, cuando utilizamos el concepto de universalización referimos, en lo sustancial, el campo de acción de la ONU y los entes multilaterales anexos a ella.

2 En noviembre de 2016 José Miguel Insulza renunció al cargo de agente de Chile ante la CIJ y fue reemplazado por el embajador Claudio Grossman.

3 "Copia feliz del edén" es el verso de una estrofa del himno nacional de Chile que Sagredo utiliza en su texto para confrontar la problemática chilena contemporánea con el discurso histórico.

4 Godoy 2011, Méndez 2009 y Ortega 2005. Godoy demuestra el carácter oficial y sistemático del saqueo de los bienes culturales del Perú durante la ocupación chilena. Méndez describe el estado de abandono en el que quedaron los veteranos chilenos de la guerra del 79 y Ortega cuestiona la versión oficial chilena sobre la Guerra del Pacífico y señala que el conflicto derivó de las políticas adoptadas por Chile para contrarrestar los efectos de la crisis mundial, tanto como para integrar a la plebe urbana con el proyecto nacional. La compilación ya mencionada de Cid y Santa Cruz (2009) es también una revisión, desde el análisis del discurso, de los principales tópicos de la narrativa oficial chilena y los imaginarios que de ella se desprenden. Cavieres 2013, 2014 y 2016, Entre otras. Véase también la compilación titulada Las Historias que nos unen del Dr. Sergio González y el suscrito, que cuenta con una edición chilena y una peruana publicadas en 2013 y 2014, respectivamente.

5 Es importante destacar, a este nivel, el esfuerzo de Generación de Diálogo, grupo binacional peruano-chileno que aglutina personalidades de ambos países, que se reúne dos veces al año y que ha dado a luz varias publicaciones, algunas de estas han sido escritas mancomunadamente por autores de ambos países. Véase http://www.generaciondedialogo. org/

\section{Notas periodísticas}

Insulza, J.M. 26 de noviembre de 2015. "Hay que contrarrestar la imagen de que actuamos como una fortaleza sitiada", La Tercera, p. 12.
Insulza, J.M. 14 de julio de 2016. Chile alude al origen de la Guerra del Pacífico en Contramemoria presentada en La Haya, El Mercurio, p. C6. 